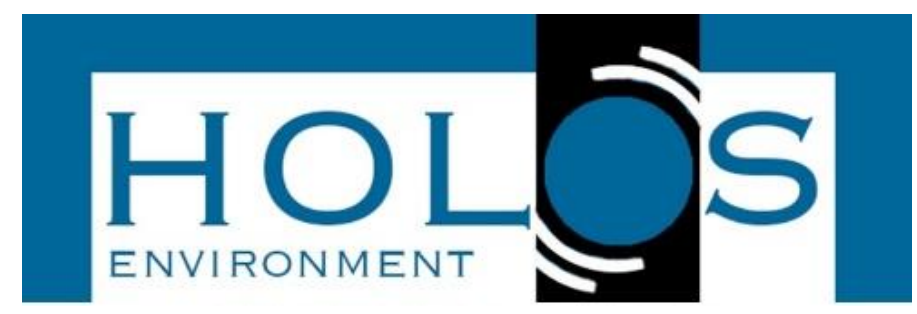

\title{
ANÁLISE COMPARATIVA DO COMPORTAMENTO HIDROLÓGICO ENTRE DUAS SUB-BACIAS DO RIO DAS MORTES - MT
}

\section{COMPARATIVE ANALYSIS OF HYDROLOGICAL BEHAVIOR BETWEEN TWO SUB-BASINS OF RIO DAS MORTES - MT}

\author{
Silvia Cristina Stupp Ghellere ${ }^{1}$
}

Artigo recebido em: 20/02/2019 e aceito para publicação em: 06/05/2019.

DOI: http://dx.doi.org/10.14295/holos.v19i1.12261

Resumo: O presente estudo teve como objetivo conhecer o comportamento hidrológico em duas subbacias do Rio das Mortes, uma representando a porção do Alto Rio das Mortes e outra representando o Baixo Rio das Mortes e compará-las. Para tanto buscou-se informações hidrológicas no Sistema de Informações Hidrológicas da Agência Nacional de Águas, trabalhou-se as informações em Software QGIS 2.12 e realizou-se análise estatística no Microsoft Excel. Como o período de disponibilidade de dados hidrológicos é diferente optou-se por analisar os dados do Alto Rio das Mortes dos últimos 30 anos e comparar com a sub-bacia representativa do Baixo Rio das Mortes os dados dos últimos 15 anos. A sub-bacia do Baixo Rio das Mortes apresentou maior volume precipitado por unidade de área enquanto que a sub-bacia do Alto Rio das Mortes apresentou maior volume escoado anual por unidade de área. Identificou-se tendência negativa no volume anual precipitado ao longo de 30 anos no Alto Rio das Mortes enquanto que o Baixo Rio das Mortes apresentou leve tendência positiva dos volumes mensais máximos precipitados. As duas sub-bacias apresentam como maior usuário da água a irrigação, sendo esta maior em proporção no Alto Rio das Mortes. Os coeficientes de escoamento anual no Alto Rio das Mortes variaram de 0,31 a 0,47 enquanto que na sub-bacia do Baixo Rio das Mortes variaram entre 0,20 e 0,50 . Sendo os valores do coeficientes de escoamento influenciados por fatores ambientais e sociais.

Palavras-chave: Hidrologia. Bacia hidrográfica. Rio das Mortes. Balanço hídrico. Irrigação.

Abstract: The present study had as objective to know the hydrological behavior in two sub-basins of the Rio das Mortes, one representing the portion of the Upper Rio das Mortes and another representing the Lower Rio das Mortes and comparing them. Hydrological information was sought in the Hydrological Information System of the National Water Agency, the information was worked in QGIS 2.12 Software and statistical analysis was performed in Microsoft Excel. As the period of availability of hydrological data is different, it was decided to analyze the data from the Upper Rio das Mortes of the last 30 years and compare the data of the last 15 years with the representative sub-basin of the Lower Rio das Mortes. The Lower Rio das Mortes sub-basin presented higher precipitation per unit area while the upper Rio das Mortes sub-basin had the highest annual volume per unit area. A negative trend was identified in the precipitated annual volume over 30 years in the Upper Rio das Mortes, while the Lower Rio das Mortes presented a slight positive trend in the precipitated maximum monthly volumes. The two sub-basins present irrigation as the largest user of water, which is higher in proportion in the Upper Rio das Mortes. The annual flow coefficients in the Upper Rio das Mortes ranged from 0.31 to 0.47 while in the Lower Rio das Mortes subbasin ranged from 0.20 to 0.50 . The values of the runoff coefficients are influenced by environmental and social factors.

\footnotetext{
${ }^{1}$ Universidade Federal de Mato Grosso (UFMT), Cuiabá, MT. E-mail: (sil.ghellere@gmail.com)
} 


\section{INTRODUÇÃO}

O Rio das Mortes é o principal afluente da margem esquerda do Rio Araguaia e este por sua vez é um importante rio da bacia do Rio Tocantins-Araguaia que é a quarta maior bacia brasileira (MELO; TEJERINAGARRO; MELO, 2007)

A sub-bacia do Rio das Mortes está inserida no Bioma Cerrado onde as principais regiões fitoecológicas presentes são: Savana Parque, Savana florestada, Savana Arborizada e Floresta Estacional Semidecidual (SEPLAN, 2001 apud ROSIN, 2015).

O Rio das Mortes que nasce na Serra do Roncador é considerado o mais importante tributário do canal principal, com aproximadamente $60.000 \mathrm{~km}^{2}$ de área de drenagem, flui através da margem esquerda, apresenta padrão sinuoso e transcorre ao longo da Planície do Bananal em direção paralela com o Rio Araguaia (AQUINO et al., 2009).

Ao longo dos anos as bacias hidrográficas devido ao uso antrópico passam por alterações no uso e ocupação do solo, e de acordo com Tucci \& Clarke (1997) as modificações naturais e artificiais na cobertura vegetal das bacias hidrográficas influenciam o seu comportamento hidrológico produzindo os mais variados impactos sobre o meio ambiente e a disponibilidade dos recursos hídricos.

Mais especificamente na bacia do Rio das Mortes, de acordo com Nápolis (2010) nas áreas antes de vegetação nativa que foram substituídas por outros usos, hoje predomina a agricultura, o que compromete a quantidade e qualidade de água na bacia.

Isso devido à expansão das áreas irrigadas, e a irrigação diminui a quantidade de água disponível no curso d'água (SCANLON et al., 2007).

Entretanto a irrigação é elemento importante no aumento da produção agrícola em mesma área. O que vem causando a expansão mundial da irrigação principalmente nos países em desenvolvimento (FAO, 2012).

No Brasil, então, a agricultura irrigada segue a tendência mundial sendo o maior consumidor de água. O Brasil está entre os países com maior área irrigada do planeta, embora ainda utilize apenas uma pequena parte do seu potencial para a atividade. (ANA, 2017). 
A irrigação é elemento importante para a produção nacional quando entendese que a agricultura no Brasil possui importante participação no PIB nacional. O agronegócio apresentou um aumento da vantagem corporativa em relação a outros ramos de atividade da economia, desse modo, se tornando uma opção atrativa o investimento no agronegócio (GASQUES et al., 2004).

Conhecendo-se a realidade de que a irrigação é importante para a produção agrícola nacional, que por sua vez tem importante participação no PIB nacional, é de extrema importância conhecer a capacidade de produção de água das bacias hidrográficas afetadas por este uso.

Neste estudo, a análise de duas sub-bacias adjacentes busca apresentar um comparativo desta capacidade em bacias tão próximas.

\section{MATERIAIS E MÉTODOS}

Este estudo foi realizado com a definição da área de estudo a partir de estações na bacia do Rio das Mortes com 15 anos ou mais de dados disponíveis no HIDROWEB, posteriormente realizou-se o preenchimento de falhas nos dados, a análise individual dos dados de precipitação e escoamento, em seguida obteve-se os coeficientes de escoamento, examinou-se a correlação dos dados entre as bacias e buscou-se a compreensão dos fatores intervenientes nos resultados obtidos.

\section{1 Área de estudo}

Escolheu-se as duas sub-bacias representativas do Alto e do Baixo Rio das Mortes com disponibilidade de dados maior ou igual a 15 anos. Sendo assim a subbacia representativa do Alto Rio das Mortes escolhida foi a área de captação da Estação Fluviométricas 26100000 nomeada Xavantina, localizada no Rio das Mortes, que possui 30 anos de dados hidrológicos e a sub-bacia do Rio Pindaíba representativa do Baixo Rio das Mortes escolhida foi a área de captação da Estação Fluviométricas 26150000 nomeada Rio Pindaíba, localizada no Rio Pindaíba afluente do Rio das Mortes, que possui 15 anos de dados hidrológicos no período de interesse. As duas sob responsabilidade da Agência Nacional de Águas (ANA) sendo operada pela Companhia de Pesquisa de Recursos Minerais (CPRM) a operadora. 
Como os pontos de controle são estações pré-existentes não foi possível englobar todo o Alto Rio das Mortes e todo o Baixo Rio das Mortes, sendo assim este estudo se refere à áreas representativas destas regiões.

A Figura 01 apresenta o posicionamento das sub-bacias estudadas em relação à Bacia Tocantins-Araguaia, à Bacia do Rio das Mortes, ao território nacional, ao território estadual e a variação de altitude na bacia do Rio das Mortes e sub-bacias.

O Rio Pindaíba deságua no Rio das Mortes à jusante do ponto de controle do Alto Rio das Mortes, na porção mediana da bacia entretanto enquadrada como pertencente ao Baixo Rio das Mortes devido às altitudes.

Figura 1 - Área de Estudo

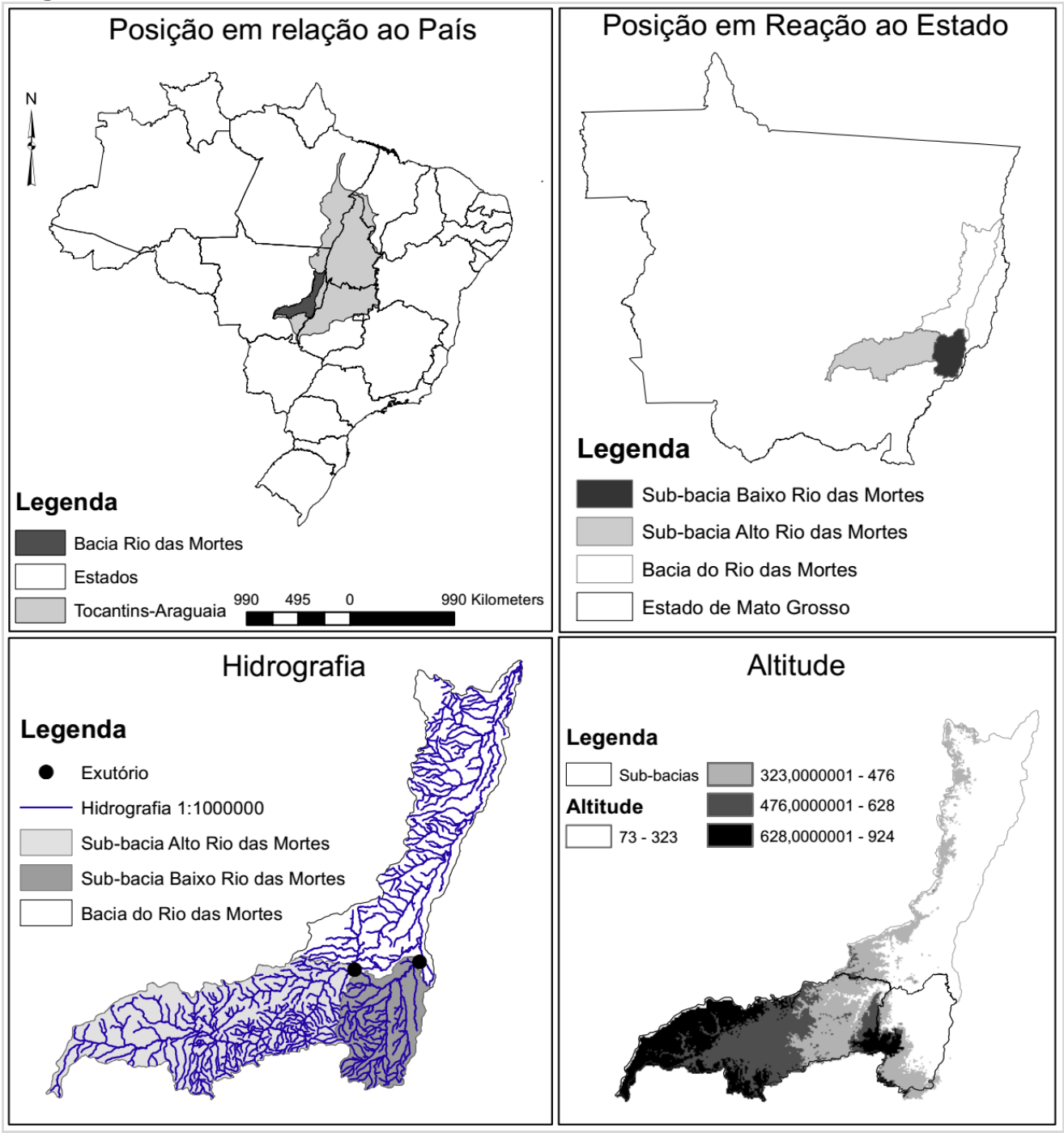




\subsection{Levantamento de informações hidrológicas}

As informações hidrológicas foram obtidas através do portal HIDROWEB (Banco de dados de informações hidrológicas da Agência Nacional de Águas).

Para facilitar a análise as duas sub-bacias foram denominadas como Alto e Baixo Rio das Mortes mesmo entendendo que não englobam totalmente o Alto e o Baixo Rio das Mortes, somente as representam.

A tabela 1 apresenta as estações fluviométricas e pluviométricas analisadas para cada sub-bacia.

Tabela 1- Estações analisadas para cada sub-bacia

\begin{tabular}{cccc}
\hline & & $\begin{array}{c}\text { Alto Rio das Mortes } \\
\text { ARM }\end{array}$ & $\begin{array}{c}\text { Baixo Rio das Mortes } \\
\text { BRM }\end{array}$ \\
\hline \multirow{2}{*}{ Exutório } & $\begin{array}{c}\text { Estação } \\
\text { Fluviométrica }\end{array}$ & $\mathbf{2 6 1 0 0 0 0 0}$ & $\mathbf{2 6 1 5 0 0 0 0}$ \\
\cline { 2 - 4 } & Nome & Xavantina & Rio Pindaíba \\
\hline \multirow{2}{*}{ Anos analisados } & $1985,1995,2000$, & 2000,2005, \\
& $2005,2010,2015$ & 2010,2015 \\
& 1452000,1552001, & 1351000,1451000, \\
Estações Pluviométricas & 1552002,1552006, & 1452000,1552001, \\
& 1453000,1454002, & 1552002,1552006, \\
& 1554005,1555005 & 1652002 \\
Estações utilizadas para preenchi- & 1454000,1554004, & - \\
mento de falhas & 1554006,1555001, & \\
\hline
\end{tabular}

\subsection{Tratamento das informações hidrológicas}

Para as estações fluviométricas os valores de vazão não disponíveis no banco de dados de medição direta foram calculados através da utilização da curva chave das estações. Sendo então a equação utilizada para o Alto Rio das Mortes a $Q=2,361$. $(h-(-39,008))^{1,035}$, enquanto para 0 Baixo Rio das Mortes $Q=0,086$. $(h-141,171)^{1,452}$, em que: $Q$ corresponde a vazão e $\mathrm{h}$ a cota do nível d'água.

As falhas foram preenchidas por regressão linear e na indisponibilidade de dados regionais, por mediana mensal quando falhas anuais eram inferiores a $25 \%$. Para as estações pluviométricas considerou-se para cada falha, as três estações mais próximas, dando preferência às estações em altitudes semelhantes. 
O método da ponderação regional consiste em $(\mathrm{X} 1, \mathrm{X} 2, \mathrm{X} 3)$. Onde para preencher as falhas no posto $\mathrm{Y}$, adota-se a Equação 1:

$P Y=\frac{1}{3} \cdot\left[\frac{P X 1}{X m 1}+\frac{P X 2}{X m 2}+\frac{P X 3}{X m 3}\right] \cdot Y m$

Em que PY é a precipitação do posto $Y$ a ser estimada:

PX1, PX2 e PX3 são as precipitações correspondentes ao mês que se deseja preencher nos outros três postos;

$Y m$ é a precipitação média do posto $Y$;

Xm1, Xm2 e Xm3 são as precipitações médias nas três estações vizinhas.

Realizou-se o descarte de anos com falhas superiores a $25 \%$ de falhas ( 3 meses).

Inicialmente efetuou-se a interpolação pelo Método dos Polígonos de Thiessen, utilizado-se Software QGis 2.12, da sub-bacia para os anos sem falhas. Posteriormente buscou-se estações para compensar os anos de falhas e para isso realizou-se novas interpolações.

No Método dos polígonos de Thiessen a área de influência de cada estação é calculada pela delimitação de área utilizando a distância mediana entre as estações vizinhas com dados disponíveis.

Nos anos sem dados ou com dados insuficientes realizou-se uma nova interpolação da bacia com estações adicionais para compensar a estação faltante e evitar influência exacerbada de algumas estações sobre a sub-bacia. Sendo assim houve a utilização de dados de estações vizinhas adicionais somente para o preenchimento de falhas desses anos.

Para realizar a comparação do comportamento hidrológico nas sub-bacias primeiramente realizou-se uma análise visual dos dados, posteriormente análise de estatística descritiva individual e conjunta e por último a análise do coeficiente de correlação e tendência.

\subsection{Obtenção do coeficiente de escoamento da bacia}

Obteve-se o coeficiente de escoamento da bacia através da seguinte Equação: 
$C=\frac{Q}{P}$

Em que $\mathbf{C}$ é o coeficiente de escoamento da bacia,

$Q$ é a vazão ( $\left.\mathrm{m}^{3} / \mathrm{mês} \mathrm{e}^{3} / \mathrm{ano}\right)$ e

$\mathbf{P}$ é a precipitação anual ( $\left.\mathrm{m}^{3} / \mathrm{mês}^{\mathrm{e}} \mathrm{m}^{3} / \mathrm{ano}\right)$.

\subsection{Análise estatística}

A análise estatística dos resultados foi realizada utilizando-se o Microsoft Excel. No qual analisou-se a estatística descritiva, o coeficiente de correlação de Pearson e a tendência.

\section{RESULTADOS E DISCUSSÕES}

\subsection{Precipitação}

A análise dos dados de precipitação indicaram que o período chuvoso nas bacias inicia no mês de outubro e dura até o mês de abril. Os meses de menor volume precipitado são os meses de junho, julho e agosto.

As precipitações no Alto Rio das Mortes representam um maior volume do que no Baixo Rio das Mortes. Sendo a correlação entre o volume precipitado nas bacias forte e positiva $(r=0,98)$.

Entretanto, ao analisar a mediana da precipitação nas bacias por unidade de área, ja que a sub-bacia do Alto Rio das Mortes é aproximadamente 2,61 vezes maior que a sub-bacia do Baixo Rio das Mortes, constatou-se que a mediana da precipitação por metro quadrado é maior no Baixo Rio das Mortes, entretanto mantém-se o coeficiente de correlação. Comportamento este ilustrado na Figura 2.

Observando a mediana mensal nota-se que nos meses de fevereiro e março ocorre uma quebra de tendência, com volume médio precipitado em fevereiro inferior ao volume médio precipitado no mês de março. 
Figura 2 -Mediana do volume precipitado mensal por unidade de área

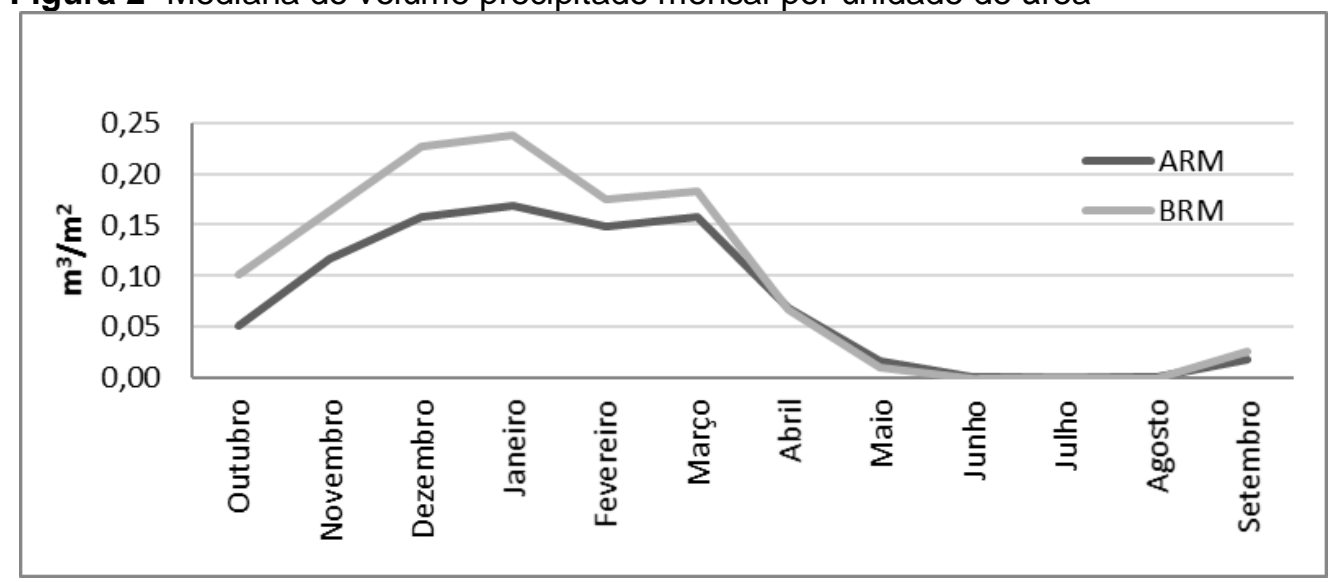

Essa característica também foi observada por Oliveira Filho et al. (2001) ao analisar o regime pluviométrico da região do Projeto Rio Formoso na Bacia do Rio Araguaia.

Constata-se que, em valores medianos, os maiores volumes precipitam no mês de janeiro nas duas sub-bacias.

Em relação ao volume precipitado anual observou-se que no Baixo Rio das Mortes o volume precipitado anual por metro quadrado foi maior (Figura 4). Enquanto o volume no Baixo Rio das Mortes não apresenta tendência clara, no Alto Rio das Mortes ha uma tendência negativa no volume anual precipitado ao longo dos anos, evidenciada pela maior disponibilidade de dados.

Analisando os valores medianos e máximos percebe-se que na sub-bacia do Alto Rio das Mortes ha também uma tendência negativa nesses valores ao longo dos anos da mesma forma que ocorreu com o volume anual. Ja na sub-bacia do Baixo Rio das Mortes ha uma leve tendência positiva dos volumes máximos.

O volume por unidade de área as duas sub-bacias não apresenta correlação. O Alto Rio das Mortes apresenta maior desvio padrão e intervalo de valores enquanto o Baixo Rio das Mortes apresenta maior média, maior valor mínimo e máximo.

Figura 3 - Volume anual , máximos e medianos precipitados (Ppt) por $\mathrm{m}^{2}$

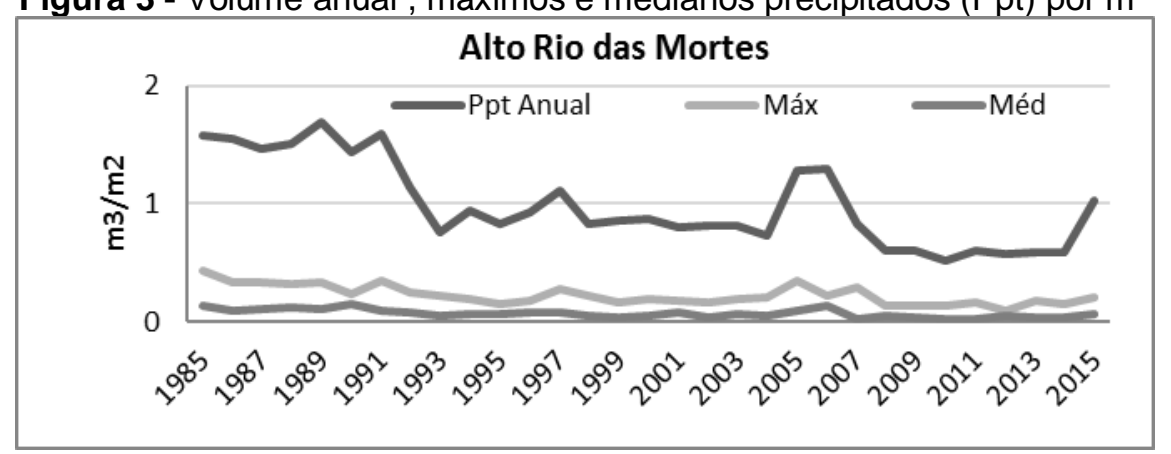


Figura 4- Volume anual , máximos e medianos precipitados (Ppt)por $\mathrm{m}^{2}$

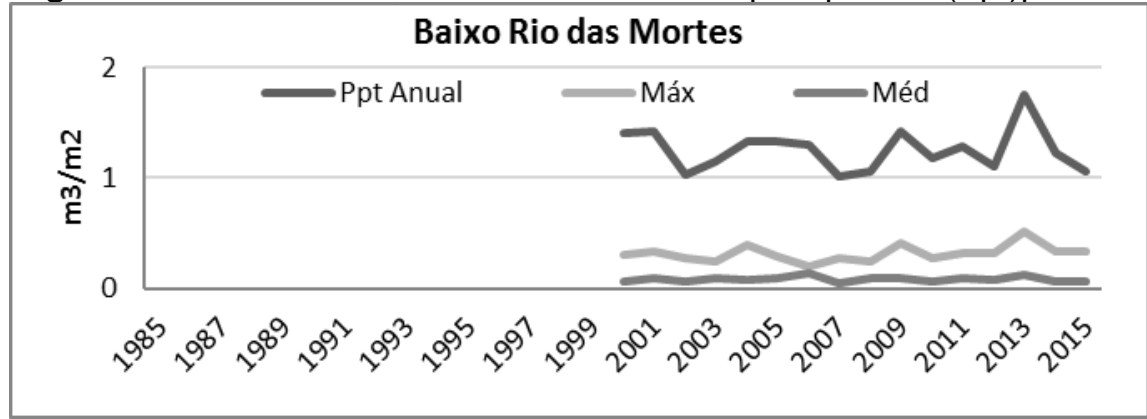

\subsection{Vazão}

Analisando as vazões registradas nas duas bacias constatou-se que no Alto Rio das Mortes (ARM) ha registro das maiores vazões. Este registro só é possível pois a estação relativa à sub-bacia do Baixo Rio das Mortes (BRM) está localizada no Rio Pindaíba, afluente do Rio das Mortes pela margem direita, e não no Rio das Mortes à jusante.

Observa-se no Figura 5 que os maiores volumes são registrados nas duas sub-bacias no mês de março e que no mês de setembro registrou-se as menores vazões. Para estes dados as duas bacias apresentaram forte correlação positiva com $r=0,99$.

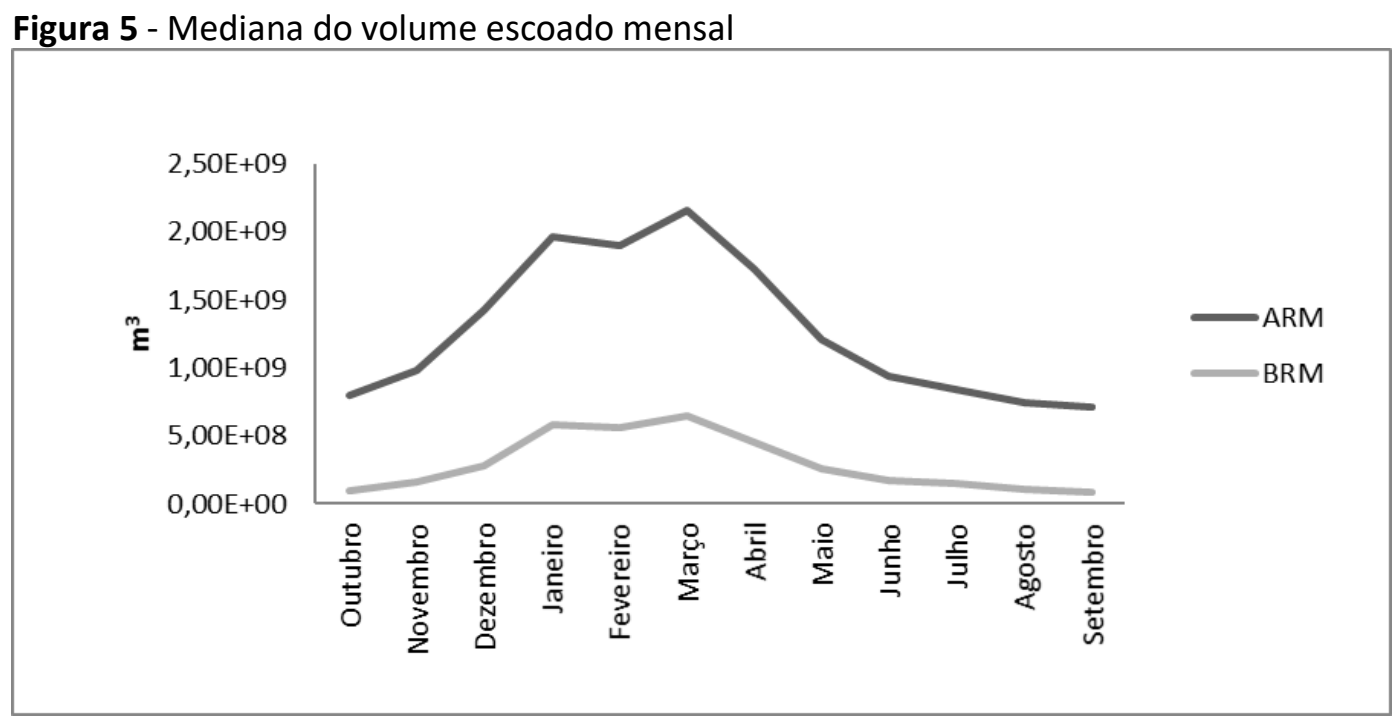

Da mesma forma, como ocorreu com os dados de precipitação, observa-se que no mês de fevereiro ocorre uma redução na vazão nas duas bacias, contradizendo a tendência de ascensão do período. Sendo um reflexo da menor precipitação na bacia neste mês em relação aos meses vizinhos. 
A fim de isolar o efeito do tamanho da bacia no escoamento obteve-se o volume anual escoado por metro quadrado. Neste, ilustrado na Figura 6, constatou-se que diferentemente da precipitação, onde na sub-bacia representativa do Baixo Rio das Mortes chove mais por metro quadrado, no escoamento a sub-bacia do Alto Rio das Mortes contribui mais em escoamento por metro quadrado no ponto de controle.

$\mathrm{Na}$ análise de correlação entre os dados de volume anual escoado observouse correlação positiva $(r=0,70)$ entre as sub-bacias.

Para estes o Alto Rio das Mortes apresenta maior média, maior valor mínimo e máximo. Enquanto o Baixo Rio das Mortes apresenta maior desvio padrão.

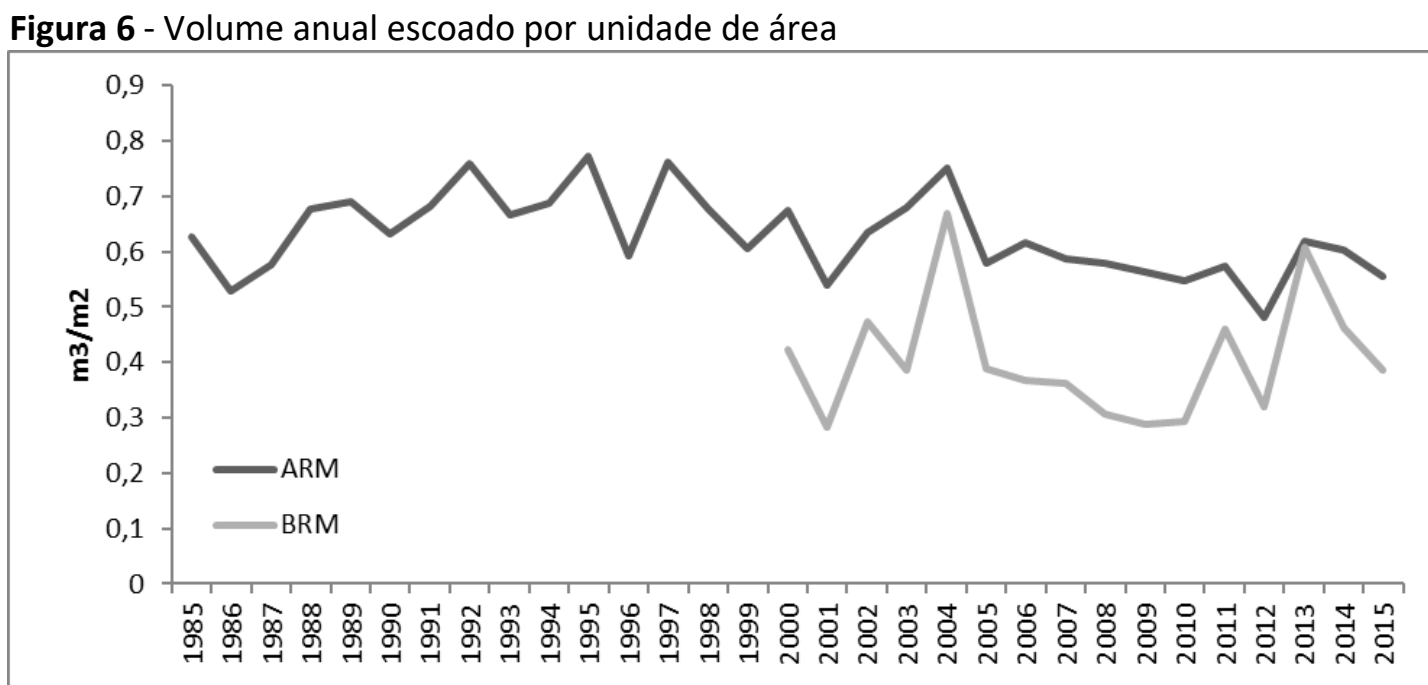

Os fatores intervenientes no escoamento se referem principalmente aos usos d'água na bacia. O que justifica que a maioria dos estudos de escoamento sejam realizados em microbacias experimentais onde ha maior controle de entradas e saídas.

Nas sub-bacias em estudo as vazões que escoam no Rio das Mortes (Alto Rio das Mortes) ou para o Rio Pindaíba (Baixo Rio das Mortes) são alteradas pela captação de água para suprir as demandas dos usuários d'água nas bacias, o que interfere na vazão registrada no ponto de controle.

De acordo com dados da Secretaria de Estado de Meio Ambiente de Mato Grosso (SEMA-MT) a sub-bacia representativa do Alto Rio das Morte possuía até Novembro de 2017 um total de 486 pontos com vazões outorgadas e na sub-bacia do Rio Pindaíba representante do Baixo Rio das Mortes foram 25 os pontos com vazões outorgadas. Destes, $98 \%$ da vazões outorgadas no Alto Rio das Mortes são 
para irrigação, onde no Baixo Rio das Mortes esta taxa é de cerca de 75\%. Enquanto no Alto Rio das Mortes os $2 \%$ restantes se referem a saneamento, no Baixo Rio das Mortes ha uma maior diversificação de uso com 16\% de uso industrial e 6\% de uso entre irrigação e criação animal, os outros 3\% são divididos entre criação animal, saneamento e serviços.

A irrigação é um uso consuntivo da água, ou seja, a água não retorna em sua totalidade ao curso d'água, reduzindo a disponibilidade hídrica do manancial (LIMA; FERREIRA; CHRISTOFIDIS, 2018).

\subsection{Coeficiente de escoamento}

A análise da mediana mensal do coeficiente de escoamento apresentou 0 comportamento hidrológico na bacia que permitiu a classificação dos meses como de período chuvoso, período seca e período de transição.

Observa-se na Figura 7 as medianas dos coeficientes mensais de escoamento nas duas sub-bacias de interesse, estas apresentam correlação forte positiva $(r=0,99)$.

Figura 7 - Mediana mensal do coeficiente de escoamento (C)

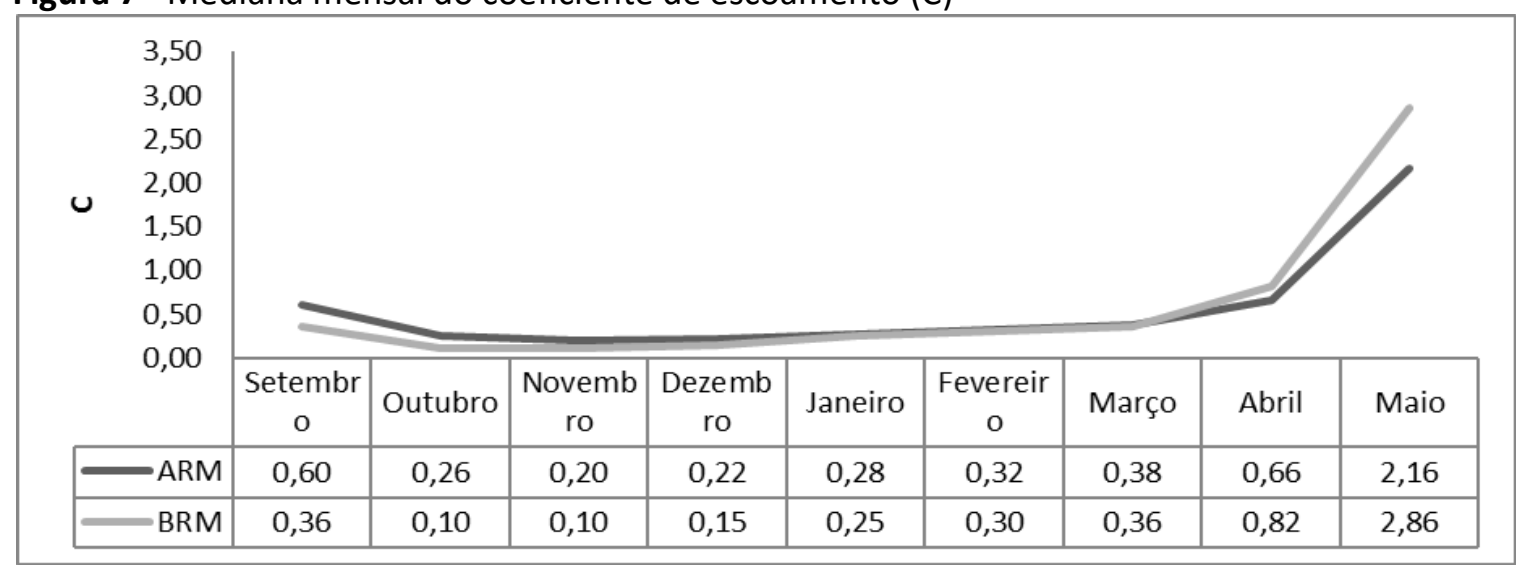

Neste foram desconsiderados os meses de junho, julho e agosto que possuem meses sem precipitação o que resulta em ausência de coeficiente. A partir de análise anterior dos dados de precipitação e vazão, estes meses já haviam sido enquadrados como meses de seca, e portanto meses em que não ha análise de coeficiente de escoamento pela ausência de precipitação.

Os meses de outubro, novembro, dezembro, janeiro, fevereiro e março foram enquadrados como meses de chuva. 
Nestes a mediana dos coeficientes mensais variou entre 0,26 e 0,38 no Alto Rio das Mortes e entre 0,10 e 0,36 no Baixo Rio das Mortes.

Os meses restantes, setembro, abril e maio foram enquadrados como meses de transição. Onde na metodologia tradicional setembro e maio são meses de seca e abril é mês chuvoso.

Estes meses foram definidos como meses de transição devido ao seu comportamento diferenciado e de transição (valores do coeficiente de escoamento que não se enquadram tanto no período de chuva como no período de seca).

Analisando a variação mensal e anual do coeficiente de escoamento do Alto Rio das Mortes observa-se que estes não apresentam tendência clara.

Analisando-se os dados de base constatou-se que ocorrem outliers nos meses de março, abril e outubro que se devem a estiagens, queda brusca no volume precipitado em relação aos meses vizinhos, enquanto a vazão se mantém estável.

De acordo com Nimer e Brandão (1989) um fator negativo dos cerrados, que contempla a bacia do Rio das Mortes, é a ocorrência de veranicos (regime de secas dentro da estação chuvoso) que pode persistir durante duas ou três semanas.

Os coeficientes de escoamento anual no Alto Rio das Mortes que variaram de 0,31 a 0,47 enquanto que na sub-bacia do Baixo Rio das Mortes variaram entre 0,20 e 0,50 .

Comparando-se os coeficientes anuais nas duas sub-bacias, apresentados na Figura 8, constatou-se a inexistência de correlação.

Figura 8 - Comparação entre os coeficientes anuais das duas sub-bacias

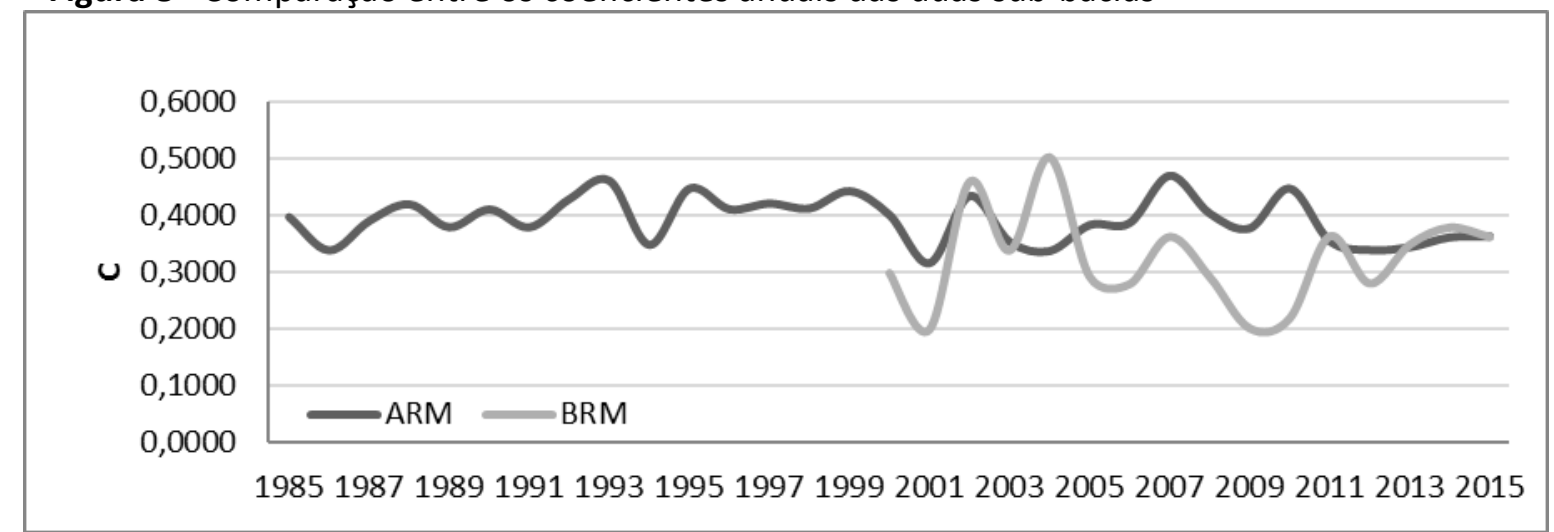




\section{INTERFERÊNCIAS NO COEFICIENTE DE ESCOAMENTO}

O coeficiente de escoamento é afetado pelo consumo d'água na bacia, que nesse estudo será entendido como a parcela do volume precipitado que não escoa nos pontos de controle, ou seja, que de alguma forma foi consumida na bacia.

A água nas sub-bacias são consumidas para manutenção dos sistemas naturais, para atividades e necessidades humanas e no retorno à atmosfera.

Observou-se que o volume consumido na sub-bacia do Alto Rio das Mortes é superior ao consumido na sub-bacia do Baixo Rio das Mortes. Entretanto considerando que a sub-bacia do Alto Rio das Mortes é cerca de 2,61 vezes maior que a sub-bacia do Baixo Rio das Mortes, analisando por unidade de área, constatou-se que o consumo nas duas sub-bacias é similar, sendo o consumo mediano levemente superior no Alto Rio da Mortes (Figura 9).

Figura 9 - Consumo de água nas sub-bacias

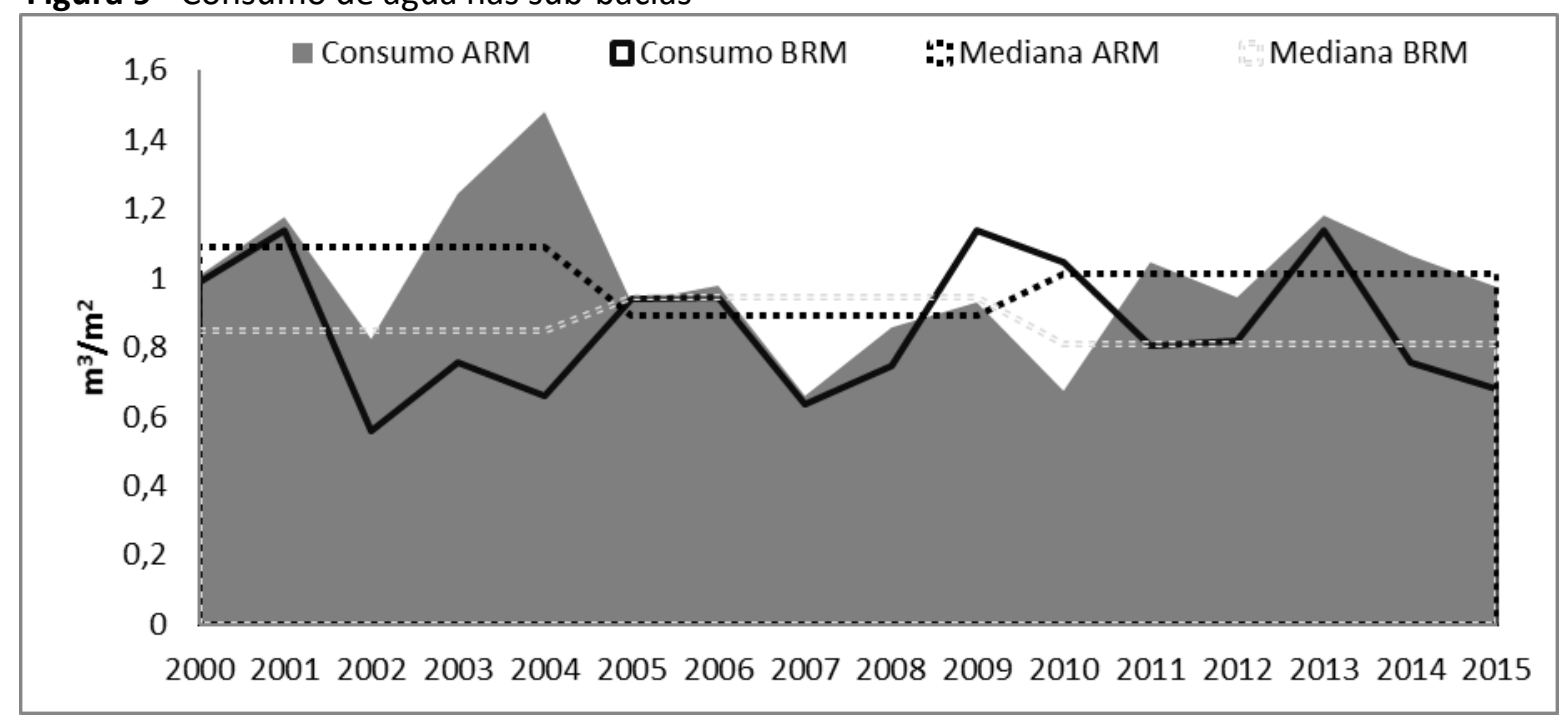

O consumo nas duas sub-bacias não apresentam correlação ou tendência. Este é influenciado por características das sub-bacias como as apresentadas na Tabela 2 . 
Tabela 2 - Fatores associados ao consumo de água nas sub-bacias

\begin{tabular}{|c|c|c|c|}
\hline Fator & ARM & BRM & Interferência \\
\hline $\begin{array}{l}\text { Forma da } \\
\text { Bacia }\end{array}$ & Alongada & Circular & $\begin{array}{l}\text { Tempo de Concentra- } \\
\text { ção, Tempo de Pico. }\end{array}$ \\
\hline $\begin{array}{l}\text { Área da } \\
\text { sub-bacia }\end{array}$ & $2.505 .565,51$ ha & $960.850,13 \mathrm{ha}$ & $\begin{array}{c}\text { Área de captação; } \\
\text { Retenção de Água no } \\
\text { solo. } \\
\text { Manutenção dos sis- } \\
\text { temas naturais }\end{array}$ \\
\hline Altitude & $323 \mathrm{~m}$ a $924 \mathrm{~m}$ & $73 \mathrm{~m}$ a $476 \mathrm{~m}$ & $\begin{array}{l}\text { Vento; Evapotranspi- } \\
\text { ração, }\end{array}$ \\
\hline Tipo de Solo* & $\begin{array}{c}\text { Latossolo Vermelho, } \\
\text { Latossolo Vermelho- } \\
\text { Amarelo, } \\
\text { Neossolo Quartzarênico }\end{array}$ & $\begin{array}{l}\text { Latossolo Vermelho- } \\
\text { Amarelo, } \\
\text { Neossolo Quartzarêni- } \\
\text { co, Plintossolo Háplico } \\
\text { Neossolo Litólico }\end{array}$ & $\begin{array}{l}\text { Escoamento superfici- } \\
\text { al, infiltração, } \\
\text { retenção de água no } \\
\text { solo, evapotranspira- } \\
\text { ção. }\end{array}$ \\
\hline Outorga d'água & $\begin{array}{c}486 \text { pontos com } \\
\text { vazões outorgadas }\end{array}$ & $\begin{array}{c}25 \text { pontos com } \\
\text { vazões outorgadas }\end{array}$ & $\begin{array}{l}\text { Redução na disponi- } \\
\text { bilidade hídrica no } \\
\text { curso d'água. }\end{array}$ \\
\hline \multirow{3}{*}{$\begin{array}{l}\text { Uso e } \\
\text { Ocupa- } \\
\text { ção do } \\
\text { Solo ** }\end{array}$} & $\begin{array}{c}76,36 \% \text { de vegetação } \\
23,64 \% \text { de área explora- } \\
\text { da }\end{array}$ & $\begin{array}{l}\text { 79,99\% de vegetação } \\
20,01 \% \text { de área explo- } \\
\text { rada }\end{array}$ & \multirow{3}{*}{$\begin{array}{l}\text { Infiltração, escoamen- } \\
\text { to superficial, evapo- } \\
\text { ração. }\end{array}$} \\
\hline & $\begin{array}{c}35,60 \% \text { de vegetação } \\
64,40 \% \text { de área explora- } \\
\text { da }\end{array}$ & $\begin{array}{c}35,14 \% \text { de vegetação } \\
64,86 \% \text { de área ex- } \\
\text { plorada } \\
\end{array}$ & \\
\hline & $\begin{array}{c}36,42 \% \text { de vegetação } \\
63,58 \% \text { de área explora- } \\
\text { da }\end{array}$ & $\begin{array}{c}45,41 \% \text { de vegetação } \\
54,59 \% \text { de área explo- } \\
\text { rada }\end{array}$ & \\
\hline $\begin{array}{l}\text { Uso } \\
\text { Agrope- } \\
\text { cuário** }\end{array}$ & Commodities e Bovinos & $\begin{array}{c}\text { Bovinos e Commodi- } \\
\text { ties }\end{array}$ & Exportação de água \\
\hline
\end{tabular}

*Informações extraídas do banco de dados do Ministério do Meio Ambiente

**GHELLERE, 2018

A forma circular da bacia no Baixo Rio das Mortes propicia um menor armazenamento d'água e consequentemente uma menor disponibilidade no período de seca, refletindo no escoamento da bacia. Isso porque de acordo com Collischonn e Dornelles (2013), uma bacia circular causaria uma concentração do escoamento superficial, ja que o escoamento de um grande numero de efluentes tenderia a chegar ao mesmo tempo no exutório. Ja na bacia alongada vai ocorrendo contribuição em vazão ao longo da bacia, tornando o escoamento mais lento.

$\mathrm{Na}$ bacia do Baixo Rio das Mortes a forma circular influenciou gerando coeficientes medianos anuais extremos (inferiores e superiores).

A sub-bacia representativa do Alto Rio das Mortes com maior área de captação, forma alongada além da predominância de solos mais profundos e menos arenosos apresenta uma tendência natural para reter a água na bacia por mais tempo o 
que promoveria um maior consumo na bacia e conseqüente menor escoamento. Entretanto ao longo dos anos houve a substituição de $63,58 \%$ de vegetação nativa principalmente por culturas agrícolas e pastagens que criou uma condição favorável ao maior escoamento superficial das águas e portanto promovendo a menor retenção de água na bacia. O que culminaria com uma ascensão nos coeficientes de escoamento ao longo dos anos. Entretanto os dados não apresentam tendência.

Da mesma forma na sub-bacia representativa do Baixo Rio das Mortes. A forma circular da bacia, sua menor extensão, a substituição de 54,6\% de sua vegetação por uso antrópico e a tendência positiva nos volumes máximos precipitados ao longo dos anos, tendem a propiciar um acréscimo nos valores de coeficiente de escoamento ao longo dos anos, o que não se verifica neste estudo.

O aumento do escoamento superficial, proporcionado pela alteração no uso do solo por atividades agropecuárias em sua maioria, tende a aumentar o volume escoado na bacia, entretanto nas duas sub-bacias analisadas neste estudo este fenômeno não foi observado. Ele pode ter ocorrido entretanto ter sido ocultado por ações como a subtração de água do corpo hídrico para irrigação, dessedentação de animais e indústria. Que promovem a remoção de água do rio e portanto a redução do volume escoado no exutório (pontos de controle).

Esta hipótese foi reforçada após levantamento de informações de outorga do uso da água nestas sub-bacias junto à Secretaria de Estado de Meio Ambiente (SEMA) de Mato Grosso que indicaram que a irrigação é o uso predominante e mais representativo de água nas mesmas. Sendo este uso consuntivo e com baixa taxa de retorno, que de acordo com ANA (2017) é em torno de $23 \%$.

Assim sendo, considera-se que os usos d'água nas sub-bacias de estudo tenham potencial para interferir na análise do coeficiente de escoamento destas subbacias. Sem as informações precisas das vazões outorgadas e do regime de uso, ja que cada produtor define um período de irrigação e a SEMA-MT não possui um arquivo digital completo, não é possível mensurar a interferência desse uso no escoamento da bacia. Dessa forma o estudo seria mais eficiente e conclusivo se realizado em área menor sem estas interferências.

\section{CONCLUSÕES}


1. Existe uma forte correlação positiva entre os volumes precipitados $(r=0,98)$ e escoados $(r=0,99)$ nas duas sub-bacias.

2. Na análise de volume por área, a precipitação é maior na bacia representativa do Baixo Rio das Mortes enquanto que o escoamento é maior na bacia representativa do Alto Rio das Mortes.

3. O Alto Rio das Mortes apresentou tendência negativa no volume precipitado ao longo dos anos enquanto que o Baixo Rio das Mortes apresentou leve tendência positiva no máximo volume precipitado anual, nos demais não apresentou tendência.

4. As maiores vazões ocorrem no mês de março enquanto as menores ocorrem em setembro.

5. A partir da análise da mediana dos coeficientes mensais definiu-se os meses de junho, julho e agosto como meses de seca, os meses de outubro, novembro, dezembro, janeiro, fevereiro e março como meses de chuva e os meses de setembro, abril e maio como meses de transição.

6. A mediana mensal dos coeficientes de escoamento nas sub-bacias variou entre 0,26 e 0,38 no Alto Rio das Mortes e entre 0,10 e 0,36 no Baixo Rio das Mortes, enquanto que os coeficientes de escoamento anual no Alto Rio das Mortes variaram de 0,31 a 0,47 e na sub-bacia do Baixo Rio das Mortes variaram entre 0,20 e 0,50 .

7. Os coeficientes de escoamento medianos mensais apresentaram forte relação positiva $(r=0,99)$ entretanto os coeficientes anuais não apresentaram correlação nem tendência.

8. O uso consuntivo para irrigação, predominante nas duas sub-bacias, a falta de dados precisos deste uso e a impossibilidade de realizar análise sem a interferência deste fator tornam o estudo inconclusivo quanto a análise de tendência do coeficiente de escoamento nas sub-bacias.

\section{AGRADECIMENTOS}

Agradeço à minha família e aos professores do Programa de Pós Graduação em Recursos Hídricos da UFMT pelo apoio emocional e técnico. 


\section{REFERÊNCIAS}

ANA. Outros usos. Agência Nacional de Águas. Acessado em: nov. 2017. Disponível em: http://www3.ana.gov.br/portal/ANA/usos-da-agua/outros-usos.

Irrigação. Atlas Irrigação. Agência Nacional de Águas. Acessado em: nov. 2017. Disponível em: http://www3.ana.gov.br/portal/ANA/usos-da-agua/irrigacao/irrigacao-1.

Capítulo 3: Usos da Água. Conjuntura recursos hídricos no Brasil 2017. Agência Nacional de Águas. Acessado em: nov. 2017. Disponível em: http://www3.ana.gov.br/portal/ANA/usos-da-agua/irrigacao/irrigacao-1.

AQUINO, Samia; LATRUBESSE, Edgardo M.; SOUZA FILHO; Edvard Elias de. Caracterização Hidrológica e Geomorfológica dos afluentes da bacia do Rio Araguaia. Revista Brasileira de Geomorfologia. Acessado em: nov. 2017. Disponível em:

http://lsie.unb.br/rbg/index.php/rbg/article/view/116/111.

COLLISCHONN, Walter e DORNELLES, Fernando. Hidrologia para engenharia e ciências ambientais. Porto Alegre: Associação Brasileira de Recursos Hídricos, 2013.

DPI INPE. Ambdata. Grupo de modelagem para estudos da biodiversidade. Disponível em: http://www.dpi.inpe.br/Ambdata/unidades administrativas.php. Acessado em: mar. 2017.

FAO. World Agriculture towards 2030/2050. The 2012 revision. Disponível em: http://www.fao.org/docrep/016/ap106e/ap106e.pdf. Acessado em: nov. 2017.

GASQUES, J.G.; REZENDE, G. C. de; VERDE, C. M. V.; SALERNO, M. S.; CONCEIÇÃO, J. C. P. R. da; CARVALHO, J. C. de S. Desempenho e crescimento do agronegócio no Brasil. Texto para discussão no1009. Brasília: Ipea, fev. 2004. Disponível em: http://www.en.ipea.gov.br/agencia/images/stories/PDFs/TDs/td 1009.pdf. Acessado em: dez. 2017.

GHELLERE, Silvia C. S. Mudança da cobertura do solo e o coeficiente de escoamento de sub-bacias do Rio das Mortes - MT. Dissertação (Mestrado) - UFMT/Cuiabá-MT. Fevereiro de 2018.

LIMA, Jorge E. F. W.; FERREIRA, Raquel S. A.; CHRISTOFIDIS, Demetrios. O uso da Irrigação no Brasil. Agência Nacional de Energia Elétrica / Instituto Interamericano de Cooperação para Agricultura. Acessado em: Novembro de 2017. Disponível em:

https://www.researchgate.net/profile/Jorge Enoch Lima/publication/228716436 O uso da I rrigacao no Brasil/links/00463539b762c64d04000000.pdf.

MATO GROSSO (MT). Economia. 23 nov. 2015. Acessado em: nov. 2017. Disponível em: http://www.mt.gov.br/economia.

MELO, Tatiana L. de; TEJERINA-GARRO, Francisco L.; MELO, Cesar E. de. Diversidade biológica da comunidade de peixes no Baixo Rio das Mortes, Mato Grosso, Brasil. Revista Brasileira de Zoologia. Curitiba, v. 24, n.3, 2007. Disponível em:

http://www.scielo.br/scielo.php?script=sci arttext\&pid=S0101-81752007000300017. Acessado em: 01 de mar. 2019. 
NÁPOLIS, Patrícia Maria Martins. Políticas públicas na bacia hidrográfica do Rio das Mortes Mato Grosso-Brasil: educação ambiental para vidas. Tese (Doutorado). São Carlos, 2010. Acessado em: fev. 2018. Disponível em:

https://repositorio.ufscar.br/bitstream/handle/ufscar/1682/3118.pdf?sequence=1\&isAllowed=y

NIMER, Edmon e BRANDÃO, Ana Maria P. M. Balanço hídrico e clima da região dos Cerrados. IBGE. Rio de Janeiro, 1989. Disponível em:

https://biblioteca.ibge.gov.br/visualizacao/livros/liv80951.pdf. Acessado em nov. 2017.

OLIVEIRA FILHO, Jair da Costa; PINTO, Eder Soares; SABOYA, Luciano Marcelo Fallé;

PERON, Antonio José; CAETANO, Gaspar F. Caracterização do regime pluviometrico da região do Projeto Rio Formoso na Bacia do Araguaia, TO., Brasil. Acta Amazonica, v. 31, n. 2, p. 221-226, 2001. Acessado em: nov. 2017. Disponível em:

http://www.scielo.br/pdf/aa/v31n2/1809-4392-aa-31-2-0221.pdf.

ROSIN, Cássia. Análise de tendências hidrológicas na Bacia do Rio das Mortes e suas relações com as mudanças na cobertura do solo. Dissertação (Mestrado) UFMT/Cuiabá-MT. Fev. 2015.

SCANLON, Bridget R.; JOLLY, lan; SOPHOCLEOUS, Marios; ZHANG, Lu. Global impacts of conversions from natural to agriculturas ecosystems on water resources: Quantity versus quality. Agu Publications. Water Resources Research, 27 mar. 2007. Acessado em: nov. 2017. Disponível em: http://onlinelibrary.wiley.com/doi/10.1029/2006WR005486/full.

SEMA. Arquivos digitais. Secretaria de Estado de Meio Ambiente de Mato Grosso. Novembro de 2017.

TUCCI, Carlos E..M. \& CLARKE, Robin T. Impacto das mudanças da cobertura vegetal no escoamento: Revisão. RBRH - Revista Brasileira de Recursos Hídricos, v. 2 n.1, p. 135152, Jan./Jun. 1997. Disponível em:

https://www.abrh.org.br/SGCv3/index.php?PUB=1\&ID=57\&SUMARIO=763. Acessado em: mar. 2017.

USGS. EarthExplorer. Acessado em: out. 2016. Disponível em:

https://earthexplorer.usgs.gov/. 